\title{
A Thematic Analysis on Vedic Mathematics and Its Importance
}

\author{
Sher Singh Raikhola1, Dinesh Panthi2* ${ }^{*}$, Eka Ratna Acharya ${ }^{3}$, Kanhaiya Jha ${ }^{4}$ \\ ${ }^{1}$ Department of Mathematics, Bhaktapur Multiple Campus, Tribhuvan University, Bhaktapur, Nepal \\ ${ }^{2}$ Department of Mathematics, Valmeeki Campus, Nepal Sanskrit University, Kathmandu, Nepal \\ ${ }^{3}$ Central Department of Education, Tribhuvan University, Kathmandu, Nepal \\ ${ }^{4}$ School of Science, Kathmandu University, Dhulikhel, Nepal \\ Email: raikholasher@gmail.com, ${ }^{\star}$ panthid06@gmail.com
}

How to cite this paper: Raikhola, S.S., Panthi, D., Acharya, E.R. and Jha, K. (2020) A Thematic Analysis on Vedic Mathematics and Its Importance. Open Access Library Journal, 7: e6665.

https://doi.org/10.4236/oalib.1106665

Received: July 26, 2020

Accepted: August 25, 2020

Published: August 28, 2020

Copyright (C) 2020 by author(s) and Open Access Library Inc.

This work is licensed under the Creative

Commons Attribution International

License (CC BY 4.0).

http://creativecommons.org/licenses/by/4.0/

(c) (i) Open Access

\begin{abstract}
Vedic mathematics is found to be very effective and sound for mental calculations in mathematics. Sutras and sub sutras have beautiful and striking tricks for fast and easy for mathematical calculations. In this article, we explore on importance of Vedic Mathematics with thematic analysis. Vedic Math provides more systematic, simplified, unified and faster than the conventional system. A significant and interesting invention which has led to various applications in all the disciplines is the development of Vedic Math approach. The importance of Vedic mathematics can be characterized as: 1) mathematical calculations, 2) speed, 3) classic approach, 4) fun and interesting, and 5) individual confidence.
\end{abstract}

\section{Subject Areas}

Numerical Mathematics

\section{Keywords}

Vedic Math, Mathematical Calculations, Classic Approach, Vedic Sutra, NVivo 12 Pro, FFT

\section{Introduction}

The Sanskrit word "Veda" means knowledge. The word Veda literarily means the fountain head and illimitable knowledge store. Therefore, the Veda contains all knowledge that is essential for mankind. Veda is the original word for Vedic. The word Veda also refers to the sacred ancient Hindu literature which is di- 
vided into four parts: the Rig-Veda, the Yajur Veda, the Sam Veda and the Atharva Veda. The Atharva Veda is sometimes called the "Veda of magical formulae". It is the primary source of information about Vedic culture. Subjects covered in the Vedas include Grammar, Astronomy, Architecture, Psychology, Philosophy, Economics, Medicine and Archery [1].

"Vedic Mathematics" is a very good technique or method of calculations based on simple rule and principles. By this technique, any mathematical problem whether it is arithmetic or algebra or geometry or trigonometric can be solved [2].

Vedic mathematics is an old technique that consists of sixteen sutras and thirteen sub sutras. It simplifies the fundamental arithmetic operations. It also solves algebraic concepts like simultaneous equation, quadratic equations, factorization of cubic equations etc. more effectively than the traditional approach. Vedic Mathematics can speed up mathematical calculations such as Arithmetic, Algebra, Trigonometry and Geometry. It reduces the time to solve a mathematical problem and boosts the student confidence [3].

Vedic Mathematics works faster in areas of Trigonometry, Co-ordinate Geometry and Calculus, in the same effective manner. It helps students in minimizing careless mistakes. It is simple and one-line approach. Moreover, it has an inbuilt system of a series of checks. Medical research has proved that our brain weight may increase by five percent if we do not have mental exercise and brain weight once increased, cannot be reduced [4].

According to a study conducted some years ago, by a university in America, the constant use of calculators for more than twenty years by a person atrophies his brain significantly. Through Vedic Mathematics, we use both parts of our brain, thereby, keeping us mentally fit [5].

Vedic mathematics is an old system of Mathematics. Vedic mathematics was rediscovered early in early twentieth century by Sri Bharati Krishna Tirthji [6].

Vedic mathematics is known to be the ancient system in Indian mathematics which was re-explored Vedas in $18^{\text {th }}$ to $19^{\text {th }}$ Century by Sri Bharati Krishna Tirthaji. He developed sixteen sutras (formulae) and thirteen sub-sutras (sub-formula) to understand the mathematics. In Sanskrit, the terms sutra means "Thread of Knowledge". In English, sutra means formula. Swami Bharati Krishna Tirthji developed methods and techniques for amplifying the principles contained in the aphorisms and their corollaries, and called it Vedic Mathematics [7].

Vedic mathematics [6] is useful for basic and complex mathematical operations. The methods provided in the book for basic mathematics are easy but powerful. Large calculation on division, multiplications, addition, and subtraction can be performed easily by using Vedic tricks and formulae. Vedic Sutras and tricks provide beautiful and striking methods that is systematic than modern system of mathematics. Vedic mathematics provides the integrated structure of mathematics that is complementary, direct and easy. The Vedic system allows children to use these principles to simplify a math problem to a level that they 
can master and build their "Number Sense". Calculating in Vedic Mathematics is like playing mind game and results can be digging out very shortly like reading words. The book provides varieties of sutras (formulas) to solve mathematical problems in a creative, interesting and intelligent way. It will support to take advantage in mathematics and logic that help our children to excel in the classroom and beyond [8]. It can induce creativity in intelligent pupils, while helping slow-learners grasp the basic concepts of mathematics. A wider use of Vedic math can undoubtedly generate interest in a subject that is generally dreaded by children [9].

Vedic Mathematics [6] contains 16 formulas and 13 sub-formulas. These sutras are used in solving complex computations, and executing them manually. The algorithms and principles are given in Urdhvatiryakbhyam sutra is used for vertical and crosswise multiplication [10]. Vedic multiplier is based upon this sutra. Array multiplication is its primary source. In the design and implementation of Triyakbhyam were done and the speed was compared with Nikhilam sutra, squaring and cubing algorithm [5].

\section{Objectives and Methodology}

Bajaj argued Vedic Mathematics allows increasing people's confidence by applying Sutra to solve the mathematical problems [4]. It also suggested creativity to calculate problems that is related to Vedic Mathematics. Agarwal, Matta and Aryafound Vedic mathematics is an efficient algorithm for speedy calculations of math problems [2]. So, in this regard, this study has been carried out to study about the Vedic Mathematics and its importance in the mathematics. That is why, the researchers showed interest to undertake this research. The qualitative research aims to discover the meaning through the patterns of observed information. It emerges after the keen observation, proper documentation and careful analysis of the research topic. This study has set the objectives to find out the importance of Vedic Math in the modern era to make a word cloud of Vedic Mathematics.This study mainly focuses on Vedic Mathematics and its importance in modern era. In order to explore the importance of Vedic Mathematics, the researcher has collected literature explaining the importance of Vedic mathematics.

The researchers used thematic analysis approach to analyze the available literatures to highlight the major theme of contribution of Vedic mathematics in the modern era. Researchers collected published works as its data and subjects them to a careful analysis that usually includes qualitative aspects. NVivo 12 Pro software is used for qualitative analysis for Thematic Analysis. World Cloud and Cluster Analysis is made to show the major theme of Vedic Math's importance in the modern era. Thematic analysis through word cloud gives importance of Vedic mathematics can be characterized as 1) mathematical calculations, 2) speed, 3) classic approach, 4) fun and interesting, and 5) individual confidence. Hence this is an exploratory study to generate theme. 


\section{Definitions of Key Terms Used}

NVivo-NVivo is a Qualitative data analysis (QDA) computer software package produced Qualitative Research Software (QSR) International.

FFT - A fast Fourier transform (FFT) is an algorithm that computes the discrete Fourier transform (DFT) of a sequence, or its inverse (IDFT). Fourier analysis converts a signal from its original domain to a representation in the frequency domain and vice versa.

Thematic Analysis-Actually, thematic analysis (TA) is a well-known method for analyzing, interpretating, and explaining data in various disciplines and fields. It has several uses. It can be applied in distinct ways in distinct fields. It is used to address lots of different research questions. It is one of the cluster of methods that focus on identifying patterned meaning across a dataset.

TA is best thought of as an umbrella term for a set of approaches for analyzing qualitative data that share a focus on identifying themes (patterns of meaning) in qualitative data.

Cluster Analysis-Cluster analysis or clustering is the method of keeping a set of objects together in such a way that objects in the same group known as clusters are similar to each other than those from other groups. It's a prime function of exploratory data mining and a well-known technique for statistical data analysis, used in many fields, including pattern recognition, image analysis, information retrieval, bioinformatics, data compression, computer graphics and machine learning.

\section{Analysis}

It is very important to learn and understand the basic concepts to make any calculation easy. These two basic concepts-base and complement are the pillars of Vedic Mathematics. These are explained below with examples.

\subsection{Base}

Bases are the numbers which start with 1 and ends with 0's. For example 10, 100, $1000,10000,100000$, and so on are called bases. The first 2-digit number is 10 and the first 3-digit number is 100 and so on. Only these kinds of numbers are considered as bases. Numbers such as 200, 300, 450, 1500 are not considered as bases.

\subsection{Complement}

When two numbers are added with each other and it results in the next nearest base, then they are called Complements of each other.

For Example,

1) Consider the number 74 . The next nearest base of 74 is 100 . By adding 26 we will get 100 . So 74 and 26 are complements to each other.

2) Consider the number 254. The next nearest base of 254 is 1000 . By adding 746 we get 1000 . So they are Complements to each other. 
3) Similarly, Complement of 3 is 7(Base is 10), Complement of 28 is 72 (Base is 100), Complement of 6545 is 3455 (Base is 10000).

\subsection{Ideas for Determination of Complement Number}

Example: Subtract 358732 from 1000000

To determine the Complement of a number can be calculated by subtracting all numbers from 9 and the last number by 10, for example; complement of 358732 can be calculate as,

$$
9999910-358732=641268
$$

$\mathrm{Or}$

$$
\begin{aligned}
& \begin{array}{llllll}
9 & 9 & 9 & 9 & 9 & 10
\end{array} \\
& \downarrow \downarrow \downarrow \downarrow \downarrow \downarrow \\
& \begin{array}{llllll}
3 & 5 & 8 & 7 & 3 & 2
\end{array} \\
& =\begin{array}{llllll}
6 & 4 & 1 & 2 & 6
\end{array}
\end{aligned}
$$

The Formula is "All from 9 and the last from 10" [6]. Similarly, the Complement of 5183 can be calculate as,

$$
99910-5183=4817
$$

\subsection{Documents Analysis}

Documents analysis also supports to thematic analysis. Documents are the reliable sources of data. Vaidya concluded that in Vedic Math approach has time and again proved to offer a huge advantage in preparation for these events as well as for an individual's holistic development [10]. It is useful in bringing back fun and interest of students in an abstruse subject like Mathematics. A systematic and developed study of Vedic Mathematics will be extremely useful for students and researchers.

Acharya made efforts to connect classical and modern approach to change the archetype in mathematics by focusing upon the indications of mathematical developments [1]. The author found applications of derivatives in solving quadratic equation and also explained the relation between the first order derivative and factors of quadratic expression, cubic expression and bi-quadratic expression. By giving examples, the author has also explained application of Vertical and Crosswise Sutra for solving successive differentiation of the product of algebraic and exponential functions and also for solving problems of Integration based on Integration by parts. Writer concludes with the help of that evidences that in 100 years before the contents have not significantly changed but algorithm and the method of solving problem has altered.

Agarwal, Matta, and Arya studied the scheme and method of FFT by applying an efficient algorithm of Vedic Math which results being speedy and dependable for calculating N-point Discrete Fourier Transform [2]. Authors have explained how to reduce algorithm of 4 bit multiplication into 4 bit multiplication by giving an example by using Urdhva-Tiryagbhyam. They have also discussed about the design of a particular FFT with the help of Vedic multiplier and adder. When 
compare to regular Fast Fourier transform, and Vedic FFT is more efficient in term of time. A combination of FFT and Vedic Mathematics will create new developments in various fields.

Aggarwal investigated on observations from "Figuring" by Shakuntala Devi and found Human computers' like Shakuntala Devi do their mental calculations, their shortcuts and tips are remarkably similar to the short cuts used in Vedic Math's secret steps [3].

Bajaj depicted that when one applies Sutra to certain questions requiring creativity and rationality, this enhances a person's self-confidence [4]. The one thing common among all math prodigies since 15th century is the desire to excel by developing innovative methods to approach the given problem. In Vedic methodology, solution to any given problem can be arrived at in two different ways-one being the implementation of the general approach \& the other one is identifying the arrangement of variables and application of situation specific formulas. As per his opinion, a significant and interesting invention which has led to various applications in all the disciplines is the development of Vedic Mathematics (VM) approach. This wide applicability can be explained by the quick \& insightful solutions obtained through basic minimum arithmetic procedure. The author has tried to compare each Vedic Sutra with algebraic proof by providing sufficient examples.

\subsection{Interpretation}

Theme Generation: Available review of literature is processed through NVivo 12 Pro and theme is generated as show in Figure 1.

Figure 1 shows the major bold type face as calculating, Vedic, contents, change, functions, individual, development, sutra, functions, disciplines, explained, mathematics, useful and so on. World Cloud generates themes as Vedic math is algebraic functions which solve the given problems and builds the confidence.

Cluster analysis is done through items clustered by word similarity. It is expressed in Figure 2.

Figure 2 shows that Vedic mathematics is clustered as mathematical calculations, speed, classic approach, fun and interest, and individual confidence. It is said that Vedic math calculation creates fund and interest and faster calculates the solution and increase individual confidence.

The Sutras apply to and cover almost every branch of Mathematics. They are applied to solve complex problems that involve a large number of mathematical operations. The proper application of sutra saves time and needs less effort in solving the problem in comparison to formal methods. As the application of the sutra is logical and rational, the solutions appear like magic. It's a matter of surprise to everyone. The computer computation is also based upon these underlying principles. They provide good methods of calculations and proper ways of thinking for their appropriate applications. 


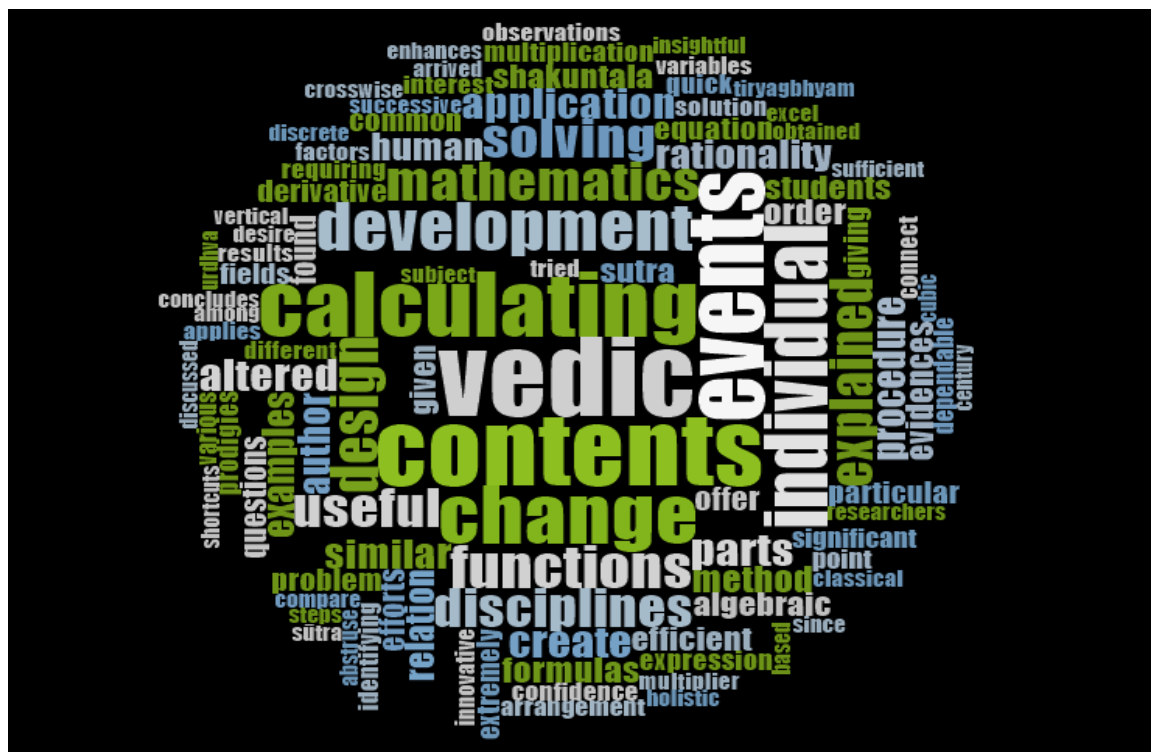

Figure 1. Word cloud. Source: Output of NVIVO 12 Pro.

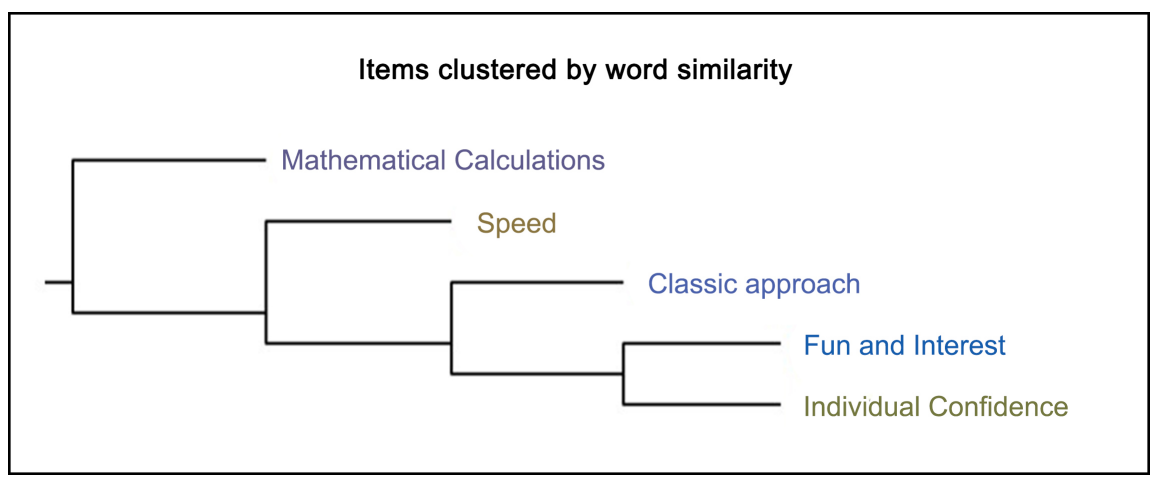

Figure 2. Cluster analysis. Source: Output of NVIVO 12 Pro.

This course on Vedic Mathematics aims to bring an integrated approach in learning mathematics with curiosity of observations and inquisitiveness. It avoids the monotony of applying traditional theories and working with them mechanically. The given explanations make the process vivid to the inquisitive learners. The logical proof of sutras eliminates the common misconceptions that the sutras are jugglery. The proper applications of sutras have improved the skills of computations of the learners significantly. It ensures both speed and accuracy as it is strictly based upon the rational and logical reasoning.

The knowledge of such methods makes the teachers able to shape the students' mind properly and enhance their talent and creativity. Applications of sutras to specific problems are not possible without rational thinking. It helps to sharpen intuition which is bottom line of the mastery of the mathematical geniuses of the past and present like Aryabhatta, Bhaskaracharya, Srinivasa Ramanujan, etc.

This course helps to use the above stated sutra and sub-sutras in learning mathematics at the secondary level in a way different from what is taught at 
present. The method has become very effective. The innovation in the presentation is the algebraic proof for every elucidation of the Sutra or the Sub-Sutra concerned.

\section{Results}

- Vedic Math provides more systematic, simplified, unified \& faster than the conventional system.

- Vedic Math gives the flexibility, fun and immense satisfaction and converts a tedious subject into a playful and blissful one which anyone can learn with smiles.

- Vedic Math with its special features has the inbuilt potential to solve the psychological problem of Mathematics anxiety.

- Vedic Math increases speed and accuracy. Mathematics, derived from the Veda, provides one line, mental and super-fast methods along with quick cross checking systems.

- Vedic mathematics provides the integrated structure of mathematics that is complementary, direct and easy.

- A significant and interesting invention which has led to various applications in all the disciplines is the development of Vedic mathematics approach.

\section{Conclusions}

Vedic Mathematics is easier to learn, faster to use and less prone to error than conventional methods. Furthermore, the techniques of Vedic Mathematics not only enable the students to solve specific mathematical problems: they also develop creativity, logical thinking and intuition.

From the above study, we can conclude that modern teaching of one way calculations are rigid and boring. Vedic Mathematics has general methods and also many methods that apply for special cases. These calculations can often be carried out independent of direction \& orientation. Because of this flexibility, students can use their own approach which promotes creativity and intuition. In this rapidly changing world, flexibility and adaptability are indispensible for success. By using Vedic Sutras, complicated and lengthy computations can be solved with greater accuracy and lesser time as compared to calculations based on conventional mathematics. Vedic Mathematics also improves memory and creates greater mental alertness. The most significant quality of Vedic Mathematics is its consistency. Because of this quality, it creates stress-free and enjoyable environment. It inspires innovations. The beautiful coherence between arithmetic and algebra is clearly visible in the Vedic system.

\section{Acknowledgements}

We would like to thank Dr. Shajeeb Kumar Shrestha, Associate Professor of Management, of Tribhuvan University, Nepal for assistance with Cluster analysis technique and methodology that greatly improved the manuscript. 


\section{Conflicts of Interest}

The authors declare no conflicts of interest regarding the publication of this paper.

\section{References}

[1] Acharya, E.R. (2015) Mathematics Hundred Years Before and Now. History Research, 3, 41-47. https://doi.org/10.11648/j.history.20150303.11

[2] Agarwal, J., Matta, V. and Arya, D. (2013) Design and Implementation of FFT Processor Using Vedic Multiplier with High Throughput. International Journal of Emerging Technology and Advanced Engineering, 3, 207-211.

[3] Aggrawal, S. (2013) Observations from Figuring. http://vedicmaths.org

[4] Bajaj, R. (2005) Vedic mathematics: The Problem Solver. Black Rose Publications.

[5] Bose, S. (2014) Vedic Mathematics. V and S Publishers, New Delhi, Edition 192.

[6] Tirthaji, S.B.K. (1965) Vedic Mathematics. Motilal Banarasidass, New Delhi.

[7] The Concept of Vedic Maths (2015) https://www.walnutexcellence.com/the-concept-of-vedic-maths/

[8] William, K. (n.d.) How to Unleash Your Natural Ability for Mental Math by Discovering the "Secret Mathematician" Hidden Deep within You! http://www.mathmonkeybrunei.com/vedic_math.php

[9] Das, S. (n.d.) The History \& Future of Vedic Maths. http://hinduism.about.com/od/vedicmaths/a/vedicmath_history_future.htm

[10] Vaidya, S.A. (2019) The Contribution of Vedic Mathematics in Advance Calculus. Doctoral Dissertation, Shri Jagdishprasad Jhabarmal Tibrewala University, Rajasthan, India. 